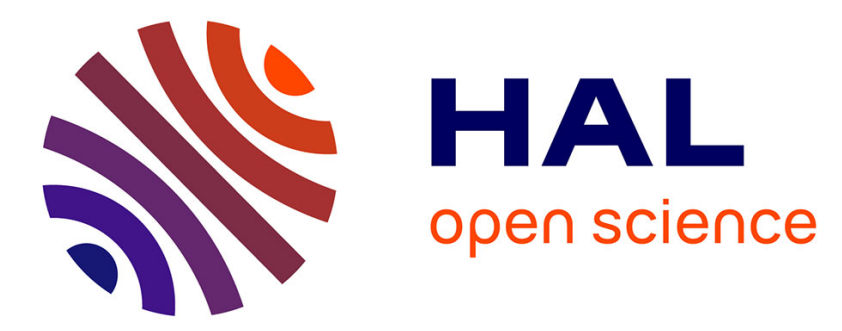

\title{
Characterization of plasma-induced phenol advanced oxidation process in a DBD reactor
}

E. Marotta, E. Ceriani, V. Shapoval, M. Schiorlin, C. Ceretta, M. Rea, C. Paradisi

\section{- To cite this version:}

E. Marotta, E. Ceriani, V. Shapoval, M. Schiorlin, C. Ceretta, et al.. Characterization of plasmainduced phenol advanced oxidation process in a DBD reactor. European Physical Journal: Applied Physics, 2011, 55 (1), 10.1051/epjap/2011110024 . hal-00719804

\section{HAL Id: hal-00719804 \\ https://hal.science/hal-00719804}

Submitted on 21 Jul 2012

HAL is a multi-disciplinary open access archive for the deposit and dissemination of scientific research documents, whether they are published or not. The documents may come from teaching and research institutions in France or abroad, or from public or private research centers.
L'archive ouverte pluridisciplinaire HAL, est destinée au dépôt et à la diffusion de documents scientifiques de niveau recherche, publiés ou non, émanant des établissements d'enseignement et de recherche français ou étrangers, des laboratoires publics ou privés. 


\title{
CHARACTERIZATION OF PLASMA INDUCED PHENOL ADVANCED OXIDATION PROCESS IN A DBD REACTOR
}

\author{
Ester Marotta ${ }^{1}$, Elisa Ceriani ${ }^{1}$, Volodymyr Shapoval ${ }^{1}$, Milko Schiorlin ${ }^{1}$, Claudio Ceretta ${ }^{1}$, \\ Massimo Rea ${ }^{2}, \underline{\text { Cristina Paradisi }}^{1}$ \\ ${ }^{1}$ Dipartimento Scienze Chimiche, Università degli Studi di Padova, via Marzolo 1, 35131 \\ Padova - Italy \\ ${ }^{2}$ Retired from Dipartimento di Ingegneria Elettrica, Università degli Studi di Padova, via \\ Gradenigo 6, 35131 Padova - Italy \\ E-mail: cristina.paradisi@unipd.it
}

\begin{abstract}
Using phenol as a model organic pollutant we studied and characterized an innovative advanced oxidation process in water using a prototype dielectric barrier discharge (DBD) reactor in which electric discharges are produced in the air above the water surface. Phenol is decomposed quite efficiently in this reactor operated at room temperature and atmospheric pressure. The process selectivity to form $\mathrm{CO}_{2}$ is, however, to be improved since a large fraction of the treated organic carbon is unaccounted for. The rate of phenol conversion increases linearly with the reciprocal of the pollutant initial concentration, suggesting the operation of a mechanism of inhibition by products as found earlier for oxidation of volatile organic pollutants in air plasmas.
\end{abstract}

\section{Introduction}

There is currently much ongoing research to exploit and apply electrical discharges for water purification [1-16]. Many different prototype reactors have been developed, including systems in which the discharge occurs into [2-5] or above the liquid [6-9], as well as hybrid reactors, which utilize both gas phase non-thermal plasma and direct liquid phase corona-like discharge in the water $[10,11]$. In addition reactors have been reported in which the solution to be treated is supplied into the discharge area as an aerosol [12] or as a falling-water film [13,14]. All these different implementations have in common the use of electrical discharges to produce, from water and molecular oxygen as precursors, some highly reactive, strongly oxidizing oxygen-based species, such as the $\mathrm{OH}$ radical, ozone and hydrogen peroxide, which are capable of attacking any organic pollutant. Such approaches are thus viewed as innovative advanced oxidation processes (AOPs), as opposed to more traditional procedures which require stoichiometric amounts of oxidizing reagents often containing heavy metals. 
Efficiency and product selectivity are critical parameters which allow for the characterization and critical evaluation of such novel plasma based processes as well as for the comparison of different experimental set-ups and discharge regimes. To this end phenol has been used by most laboratories as a model pollutant for several reasons, including its widespread diffusion, its moderate reactivity in oxidation reactions and its well characterized complex mechanism of oxidation under conditions which are closely related to the discharge induced systems under investigation here [15].

We have recently developed a dielectric barrier discharge (DBD) reactor in which an oxidizing plasma is formed at room temperature and atmospheric pressure by discharges in the air above the water to be treated [16]. We have shown that phenol is efficiently decomposed in this reactor and that its decay is accompanied by release of $\mathrm{CO}_{2}$ into the air above the treated solution. However, no quantitative data were available to allow for a determination of the process selectivity. We have since performed such quantitative determinations, as well as a study of the effect of phenol initial concentration on the process efficiency. This paper reports these new results and discusses a mechanistic hypothesis which can accommodate all the experimental findings obtained so far.

\section{Experimental Part}

\section{Materials}

Phenol and other chemicals were commercial samples of reagent grade purity. Ultrapure grade water (milliQ water) was obtained by filtration of deionized water with a Millipore system. Gases (synthetic ("pure") air, i.e. a mixture of $80 \%$ nitrogen and $20 \%$ oxygen, and various mixtures of $\mathrm{CO}_{2}$ in air used as standards for calibration purposes) were purchased from Air Liquide.

\section{Apparatus}

The apparatus and experimental procedures were described in detail in a previous article [16]. Briefly, the reactor is a glass vessel (internal dimensions $95 \times 75 \mathrm{~mm}$ and $60 \mathrm{~mm}$ height) closed by a teflon cover with four passing electrodes of stainless steel which support two parallel stainless steel wires $(0.15 \mathrm{~mm}$ diameter $\times 75 \mathrm{~mm}$ length) fixed upon their tips (Figure 1$)$. The wires are set $38 \mathrm{~mm}$ apart and about $15 \mathrm{~mm}$ above the solution to be treated. The outside surface of the reactor base is covered with a film of silver and connected to a grounded plate. Humidified air is swept through the reactor above the solution at a flow of $30 \mathrm{~mL} \cdot \mathrm{min}^{-1}$. The reactor is powered with an $\mathrm{AC}$ high voltage transformer with $16.5-18 \mathrm{kV}$ and a frequency of 
$50 \mathrm{~Hz}$ to produce discharge in the gas phase above the liquid surface. During the experiments the electrical power was maintained constant at $1.9 \mathrm{~W}$. Voltage and current profiles were monitored with a digital oscilloscope (TDS5032B, bandwidth $350 \mathrm{MHz}$, sample rate $5 \mathrm{Gs} / \mathrm{s}$ ) to assure the reproducibility of the electrical conditions.

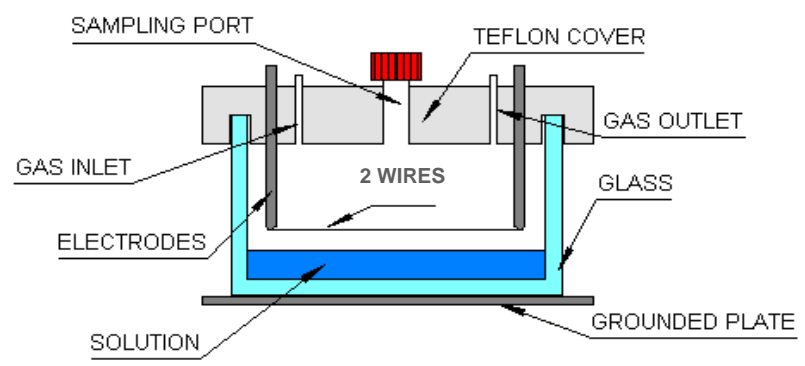

Figure 1. Schematics of DBD reactor (cross section).

\section{Procedures}

The decomposition process was monitored by measuring phenol conversion as a function of treatment time at constant applied power. To this end, at desired times the discharge was briefly interrupted and a $0.5 \mathrm{~mL}$ aliquot of the treated solution was withdrawn with a syringe from the porthole on the reactor cover and subjected to HPLC analysis (Shimadzu LC-10AT pump with a UV-Vis Shimadzu SPD-10 detector, monitoring specifically at 210 and $270 \mathrm{~nm}$ ). The fraction of residual phenol, $[\mathrm{PhOH}] /[\mathrm{PhOH}]_{0}$ (where $[\mathrm{PhOH}]_{0}$ and $[\mathrm{PhOH}]$ are the concentrations at time zero and $t$, respectively), was plotted against the treatment time and the data were fitted to equation 1 to obtain the process pseudo first order rate constant, $\mathrm{k}$.

$$
\frac{[\mathrm{PhOH}]}{[\mathrm{PhOH}]_{0}}=e^{-k t}
$$

$\mathrm{pH}$ and conductivity of the solution before application of the discharge and at the end of the treatment were monitored with a pH meter Metrohm 827 and a conductometer Metrohm 660. The gas exiting the reactor was subjected to on line FT-IR analysis (Nicolet 5700) using a 10 cm long flow cell with $\mathrm{CaF}_{2}$ windows.

\section{Results and Discussion}

Typical current and voltage profiles obtained with the DBD reactor used are shown in Figure 2. It is interesting to note how for negative corona current, pulses initiate at a voltage which is very close to zero (if not slightly positive) and continue until the voltage has reached its peak. In contrast, for positive corona, current pulses start forming at higher voltages and stop when the voltage is still high, higher than that required for the discharge onset. These observations 
can be explained considering spatial charge phenomena. Positive corona produces a strong ionic positive charge which acts as a 'corona quench' and allows for the anticipated development (or 'onset') of negative corona.

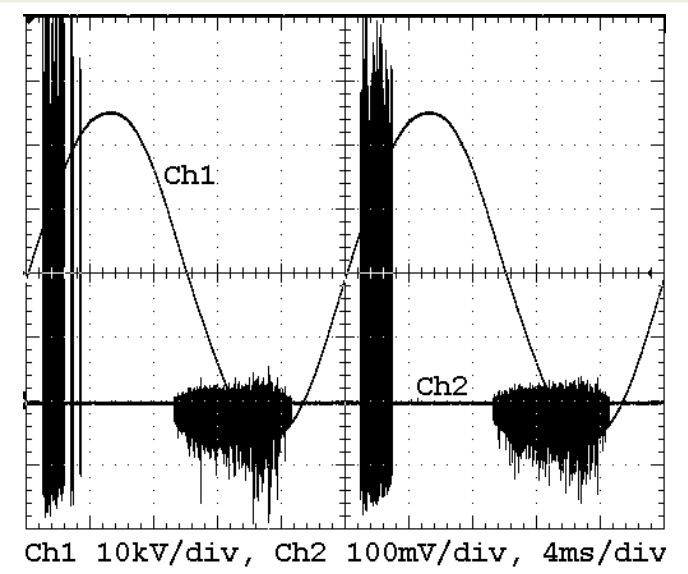

Figure 2. Current and voltage oscillograms.

The decay of phenol upon treatment with non-thermal plasma in our DBD reactor with constant power follows to a good approximation an exponential function in time. Examples of typical decay profiles are shown in Figure 3 for experiments run under identical conditions except for the initial concentration of phenol which was $2 \cdot 10^{-4}$ and $1 \cdot 10^{-4} \mathrm{M}$ for curves (a) and (b), respectively. These experiments therefore suggest that the rate of phenol decomposition depends on its initial concentration, $[\mathrm{PhOH}]_{0}$.

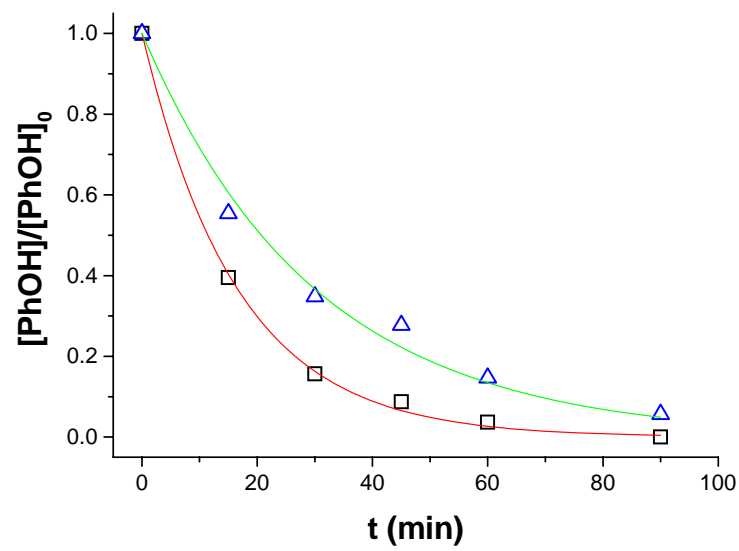

Figure 3. Effect of phenol initial concentration on its rate of decomposition in water at room temperature in the DBD reactor operated at a constant power of $1.9 \mathrm{~W}: 2 \cdot 10^{-4} \mathrm{M}(\Delta)$ and $1 \cdot 10^{-4} \mathrm{M}(\square)$, respectively. 
The results of additional experiments performed to investigate on this phenomenon are summarized in the graph of Figure 4 where the observed rate constant, k, is plotted vs the reciprocal of phenol initial concentration, $1 /[\mathrm{PhOH}]_{0}$.

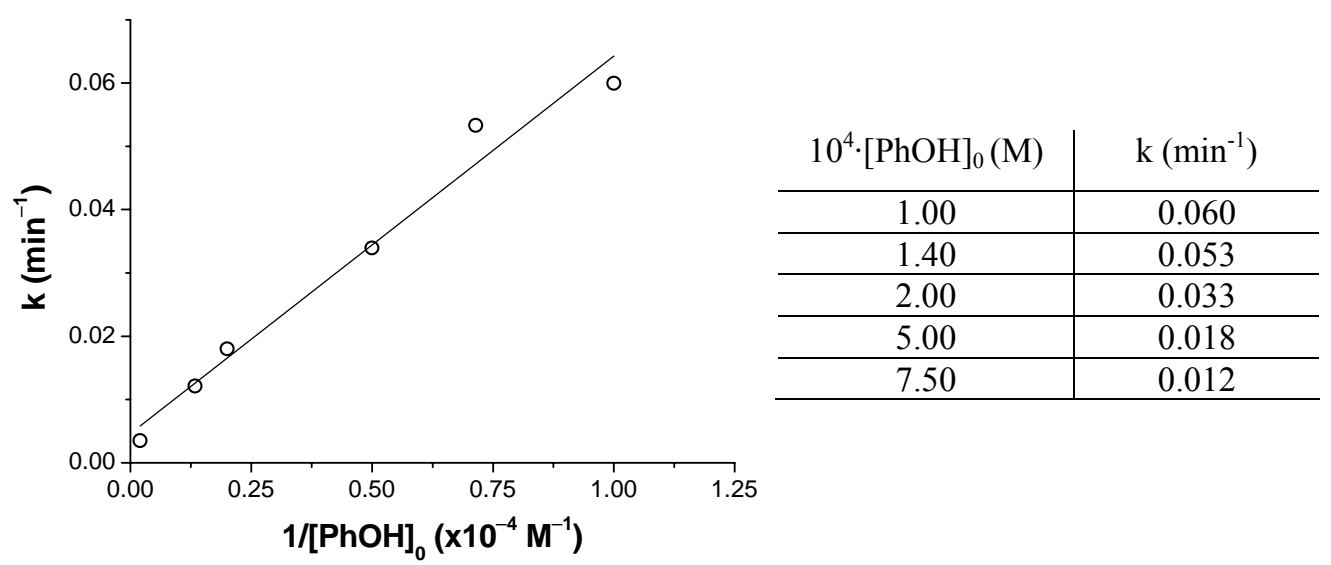

Figure 4. Dependence of rate constant on phenol initial concentration for processing in water at room temperature in the DBD reactor operated at a constant power of $1.9 \mathrm{~W}$.

The results show that within the concentration range explored $\left(1.0 \cdot 10^{-4} \div 5.0 \cdot 10^{-3} \mathrm{M}\right)$, the rate constant depends linearly, to a reasonable approximation, on the reciprocal of $[\mathrm{PhOH}]_{0}$. A similar behaviour was observed previously for non-thermal plasma induced oxidation of volatile organic compounds in air and was explained in terms of a mechanism of inhibition by products [17,18]. Applied to the system under current investigation the mechanism is described by reactions (2)-(3)

$$
\begin{array}{ll}
\mathrm{G} \rightarrow \mathrm{X} & \mathrm{S} \\
\mathrm{PhOH}+\mathrm{X} \rightarrow \mathrm{I}+\text { other products } & \mathrm{k}_{1} \\
\mathrm{I}+\mathrm{X} \rightarrow \mathrm{Z}+\text { other products } & \mathrm{k}_{2}
\end{array}
$$

where $G$ represents the gas in which the discharge is applied, $X$ represents the plasma reactive species formed at a rate $\mathrm{S}$, and $\mathrm{I}$ and $\mathrm{Z}$ are reaction intermediates. From such a scheme the following kinetic expressions are derived:

$$
\begin{aligned}
& \frac{d[X]}{d t}=S-k_{1}[X][P h O H]-k_{2}[X][I] \\
& \frac{d[P h O H]}{d t}=-k_{1}[X][P h O H]
\end{aligned}
$$

By assuming that $\mathrm{X}$ is in the stationary state, i.e. $\mathrm{d}[\mathrm{X}] / \mathrm{dt}=0$, that $\mathrm{k}_{1}$ is similar to $\mathrm{k}_{2}$, and that $[\mathrm{Z}]<<[\mathrm{I}]$ so that $[\mathrm{PhOH}]_{0}=[\mathrm{PhOH}]+[\mathrm{I}]$, as is the case in the process initial stages, then the differential equations are integrated to provide the following kinetic expression: 
$[\mathrm{PhOH}]=[\mathrm{PhOH}]_{0} e^{\left(-\mathrm{S} /[\mathrm{PhOH}]_{0}^{\cdot t)}\right.}=[\mathrm{PhOH}]_{0} e^{(-k \cdot t)}$

which predicts that the observed rate constant $\mathrm{k}$ depends directly on $\mathrm{S}$, the rate of formation of the reactive species $\mathrm{X}$, and inversely on the initial concentration of phenol, $[\mathrm{PhOH}]_{0}$.

At least as important as the efficiency, is the process product selectivity, the desired goal in treating organic pollutants being their exhaustive oxidation to $\mathrm{CO}_{2}$. We have therefore undertaken the task of determining the $\mathrm{CO}_{2}$ released in our process using quantitative FT-IR on-line analysis.

Using commercial mixtures of $\mathrm{CO}_{2}$ in air of known concentration $(49.2,249.8$ and 498.5 ppm) as standards and integrating the signal due to $\mathrm{CO}_{2}$ bond stretching (Figure 5a) we verified the stability in time and the reproducibility of the FT-IR response (Figure 5b).
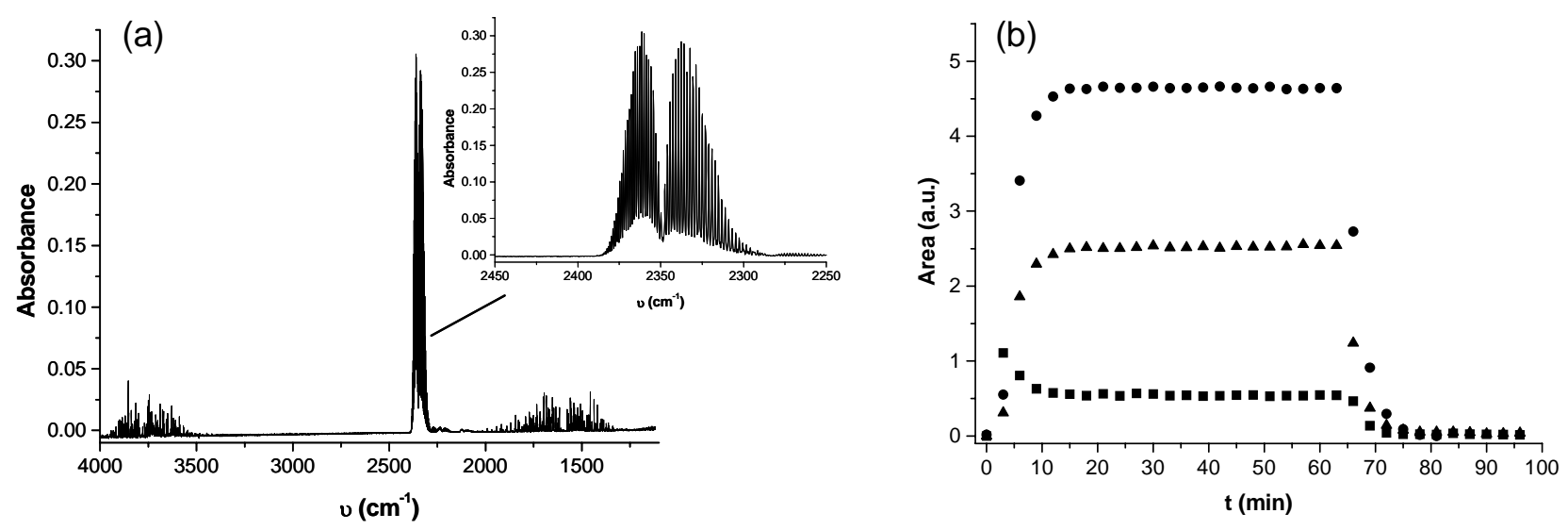

Figure 5. FT-IR analysis of $\mathrm{CO}_{2}$ (in synthetic air) flowing through the cell at a constant rate of $30 \mathrm{~mL}$ $\min ^{-1}$ : (a) FT-IR spectrum showing an expansion of the $\mathrm{CO}_{2}$ signal; (b) area (in arbitrary units) of $\mathrm{CO}_{2}$ signal recorded at $3 \mathrm{~min}$ intervals for three standard mixtures in air with $\mathrm{CO}_{2}$ concentrations of 498.5 $(\bullet), 249.8(\boldsymbol{\Delta})$ and $49.2(\boldsymbol{\bullet}) \mathrm{ppm}_{\mathrm{v}}$, respectively .

Having thus calibrated the FT-IR response, the instantaneous concentration of $\mathrm{CO}_{2}$ in the air flowing out of the DBD reactor during processing of phenol could be determined. Figure 6 shows typical time profiles (curves identified by $\circ$ and $\bullet$ symbols with reference to the lefthand side ordinate axis) for $\mathrm{CO}_{2}$ in the air flowing over the solution released from phenol processing (phenol initial concentration was $5 \cdot 10^{-4} \mathrm{M}$ in water) in two identical experiments except for the time period during which both the discharge and FT-IR monitoring were applied. 


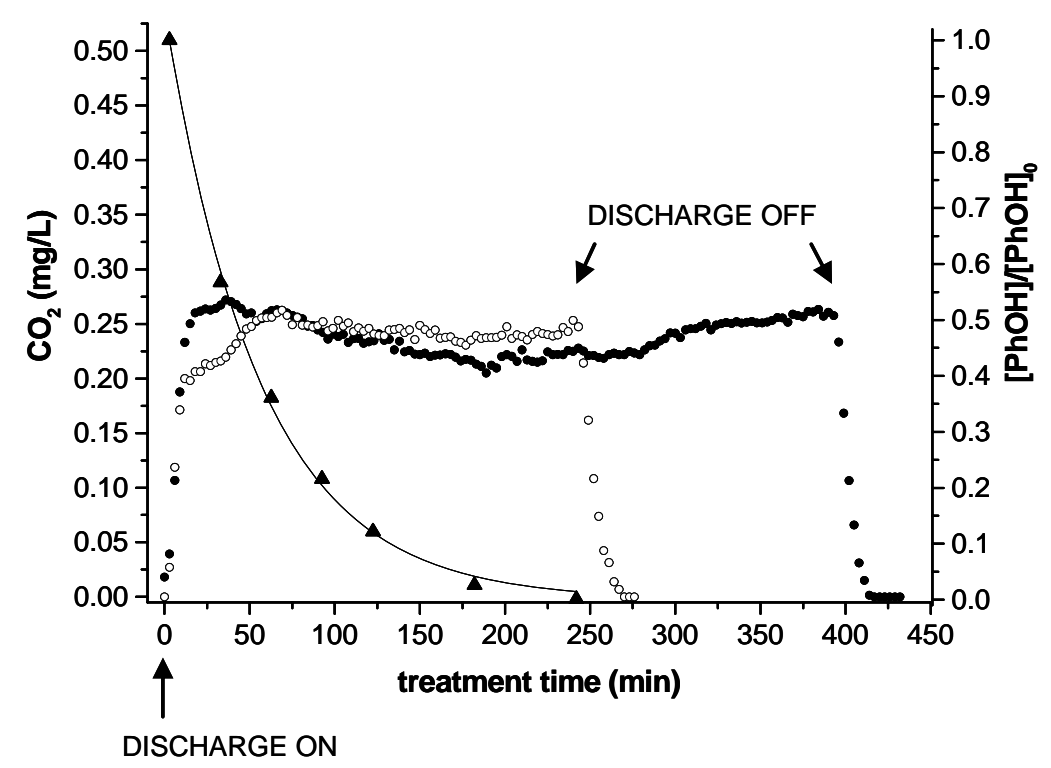

Figure 6. Time profiles for $\mathrm{CO}_{2}$ concentration (with reference to the left-hand side ordinate axis) in the air flowing out of the DBD reactor during phenol processing (phenol initial concentration was $5 \cdot 10^{-4} \mathrm{M}$ in water) for $240 \mathrm{~min}(\circ)$ and $390 \mathrm{~min}(\bullet)$, respectively. On the same time scale the decay profile of phenol is also plotted (with reference to the right-hand side ordinate axis).

It is seen that the $\mathrm{CO}_{2}$ signal rapidly rises, upon turning the discharge on, from zero to a stationary intensity which corresponds to a concentration of $0.22-0.25 \mathrm{mg} / \mathrm{L}$. In a similar rapid manner the signal intensity drops to zero when the discharge is turned off. Control experiments have shown that no $\mathrm{CO}_{2}$ is detected upon application of the discharge in the case of pure water thus confirming that $\mathrm{CO}_{2}$ is formed from the oxidation of phenol. Figure 6 also shows that the discharge induced production of $\mathrm{CO}_{2}$ progresses well beyond the time necessary for phenol consumption (the decay profile of phenol in these experiments is shown on the same time scale, with the symbol $\boldsymbol{\Delta}$ and with reference to the right-hand side ordinate axis). These observations clearly demonstrate that some intermediate species are formed which are oxidized to $\mathrm{CO}_{2}$ more slowly than phenol.

Since a constant gas flow rate was used throughout these experiments $(30 \mathrm{~mL} / \mathrm{min})$, integration of the concentration vs time curves reported in Figure 6 yields the mass of $\mathrm{CO}_{2}$ formed during the selected treatment time. It is thus found that after $240 \mathrm{~min}$, a treatment time sufficient to decompose completely phenol, only $1.77 \mathrm{mg}$ of $\mathrm{CO}_{2}$ were produced corresponding to a process selectivity of $19 \%$. In other words, $81 \%$ of the total organic carbon originally present as phenol remains undetected. By extending the treatment time to $390 \mathrm{~min}$, well beyond the time required for phenol complete conversion, more $\mathrm{CO}_{2}$ is being produced, 
reaching a total amount of $2.84 \mathrm{mg}$, which corresponds to $31 \%$ of the total organic carbon subjected to the oxidation process.

These results thus show that some carbon-containing organic materials are present in the system, which are more slowly oxidized than the precursor phenol. We have previously [16] identified by means of HPLC analysis with UV-VIS and MS and $\mathrm{MS}^{\mathrm{n}}$ detectors a few organic byproducts including dihydroxybenzenes, muconic acids and maleic acid, which are known intermediates along the complex reaction scheme leading from phenol to $\mathrm{CO}_{2}$. Quantitation of these byproducts and search and analysis of other C-containing materials possibly formed in this process are underway in our laboratory.

\section{References}

1. A. Fridman, Plasma Chemistry, (Cambridge University Press, Cambridge, 2008)

2. P. Sunka, V. Babicky, M. Clupek, P. Lukes, M. Simek, J. Schmidt, M. Cernak, Plasma Sources Sci. Technol. 8, 258 (1999)

3. B. Sun, M. Sato, J.S. Clements, Environ. Sci. Technol. 34, 509 (2000)

4. B.R. Locke, M. Sato, P. Sunka, M.R. Hoffmann, J.-S. Chang, Ind. Eng. Chem. Res. 45, 882 (2006)

5. M. Dors, E. Metel, J. Mizeraczyk, Int. J. Plasma Environ. Sci. Technol. 1, 76 (2007)

6. J. L. Brisset, J. Appl. Electrochem. 27, 179 (1997)

7. N. Sano, T. Kawashima, J. Fujikawa, T. Fujimoto, T. Kitai, T. Kanki, A. Toyoda, Ind. Eng. Chem. Res. 41, 5906 (2002)

8. L.R. Grabowski, E.M. van Veldhuizen, A.J.M. Pemen, W.R. Rutgers, Plasma Chem. Plasma Process. 26, 3 (2006)

9. M. Sato, T. Tokutake, T. Ohshima, A.T. Sugiarto, IEEE Trans. Ind. Appl. 44, 1397 (2008)

10. P. Lukes, A.T. Appleton, B.R. Locke, IEEE Trans. Ind. Appl. 40, 60 (2004)

11. D.R. Grymonpre, W.C. Finney, R.J. Clark, B.R. Locke, Ind. Eng. Chem. Res. 43, 1975 (2004)

12. R. Burlica, B.R. Locke, IEEE Trans. Ind. Appl. 44, 482 (2008)

13. N. Sano, D. Yamamoto, T. Kanki, A. Toyoda, Ind. Eng. Chem. Res. 42, 5423 (2003)

14. S. Ognier, D. Iya-sou, C. Fourmond, S. Cavadias, Plasma Chem. Plasma Process. 29, 261 (2009)

15. J.A. Zazo, J.A. Casas, A.F. Mohedano, M.A. Gilarranz, J.J. Rodriäguez, Environ. Sci. Technol. 39, 9295 (2005) 
16. E. Marotta, M. Schiorlin, X. Ren, M. Rea, C. Paradisi, accepted for publication in Plasma Process. Polym.

17. C. Slater, D.H. Douglas-Hamilton, J. Appl. Phys. 52, 5820 (1981)

18. E. Marotta, M. Schiorlin, M. Rea, C. Paradisi, J. Phys. D-Appl. Phys. 43, 124011 (2010) 